\title{
Cyclic Loading Impact on Screw Loosening of Internally Connected Implants: An Experimental Study
}

\author{
1,2Mohamed Y Abdelfattah, ${ }^{3}$ Mohammed K Fahmi
}

\begin{abstract}
Aim: The aim of this study was to assess the impact of cyclic loading on screws attaching four different abutments to internally connected implants.
\end{abstract}

Materials and methods: Four groups (seven implants each) of dissimilar abutments: Straumann solid abutment (group I), southern implants solid abutment (group II), implant direct straight abutment (group III), and Blue Sky Bio regular platform abutment (group IV). Abutments were connected to Straumann tissue-level implants. Each implant was rigidly secured in a stainless steel cylindrical jig. A torque controller was used to tighten the abutments at $35 \mathrm{Ncm}$. A $150 \mathrm{~N}$ cyclic load for 1 million cycles was applied to the implant at a $30^{\circ}$ angle to the long axis to the implants. Periotest values (PTVs) were measured before and after cyclic loading and a digital torque gauge was used to detect the removal torque values (RTVs) of abutments. The data were analyzed statistically using SPSS statistical software. Kruskal-Wallis tests and one-way analysis of variance (ANOVA) were used to compare RTVs and PTVs after application of equal loads for each group. The Spearman correlation coefficient was applied to compare RTVs and PTVs after loading.

Results: The Straumann solid abutment and the southern implants abutment showed no mechanical failures. Screws fracture was noted in nearly $85 \%$ of implant direct abutment, and $55 \%$ of the Blue Sky Bio abutments. The final mean PTV of the Blue Sky Bio abutments, the southern implants, and implant direct straight abutment was considerably higher than the final mean PTVs of Straumann solid abutment. The initial mean PTV $(-4.36 \pm 0.47)$ was lower than the final mean PTV $(4.85 \pm 5.58)$. The Straumann solid abutment RTVs values were considerably higher than that of the other abutments.

Conclusion: Abutments from the different manufacturers have different physical and chemical characteristics so there will be a potential risk of mechanical failure when the interchangeable abutments are used.

\footnotetext{
${ }^{1}$ Lecturer, ${ }^{2,3}$ Assistant Professor

${ }^{1}$ Department of Prosthodontics, Faculty of Dentistry, Tanta University, Egypt

${ }^{2}$ Department of Prosthodontics, Faculty of Dentistry, Taif University, Taif, Kingdom of Saudi Arabia

${ }^{3}$ Department of Restorative Dental Sciences, Faculty of Dentistry, Taif University, Taif, Kingdom of Saudi Arabia

Corresponding Author: Mohamed Y Abdelfattah, Lecturer, Department of Prosthodontics, Faculty of Dentistry, Tanta University, Egypt, e-mail: m.yousef@tudent.edu.sa
}

Clinical significance: The use of an abutment manufactured by the same implant company is highly recommended for the avoidance of loosening of the abutment screws.

Keywords: Abutments, Cyclic loading, Implant, Screw loosening.

How to cite this article: Abdelfattah MY, Fahmi MK. Cyclic Loading Impact on Screw Loosening of Internally Connected Implants: An Experimental Study. Int J Prosthodont Restor Dent 2018;8(4):102-107.

\section{Source of support: Nil}

Conflict of interest: None

\section{INTRODUCTION}

The implant-abutment connection is considered the core stone for implant success. ${ }^{1}$ In spite of the occurrence of serious mechanical problems, such as screw loosening which may end with component fracture. ${ }^{2-4}$ Screw loosening has been reported for all types of prostheses; including single- and multiple-unit restorations. ${ }^{3}$ Such failures are especially common in single implants in the posterior region, since they bear continuous forces from chewing, resulting in bending moments. Adequate preload, the accurate fit of the implant components, and basic anti-rotational characteristics at the implantabutment interface are the most important factors for screw joint stability. A variety of implants and abutments in the market permits the interchangeability of their products. Following the introduction of the ITI implant system (Institut Straumann), several alternative systems (implants and components) closely resembling the original ITI designs and treatment protocol were introduced. ${ }^{5,6}$

Currently, different manufacturers produce clinically interchangeable abutments. However, there is a lack of information about screw loosening when interchangeable abutments from different companies are used. The purpose of current research, therefore, was to evaluate the cyclic loading effect on the screw behavior of different abutments connected to ITI implants.

\section{MATERIALS AND METHODS}

Different abutments that were divided into four abutment groups of seven implants each (all Straumann SLA 4.1 $\mathrm{mm}$ width, $10 \mathrm{~mm}$ length implant, Institut Straumann) as shown in Table 1. Abutments were connected to 
Straumann tissue-level implants (Fig. 1). The implants were connected to customized stainless steel jigs at 30 degrees from the long axis of the implant to receive load (Fig. 2). The jig was fabricated according to the ISO standard 14801 for the dentistry-fatigue test for endosseous dental implants (Fig. 3).

The implants were connected to customized stainless steel jigs at 30 degrees from the long axis of the implant to receive load (Fig. 2). The jig was fabricated according to the ISO standard 14801 for the dentistry-fatigue

Table 1: Abutment used in the study

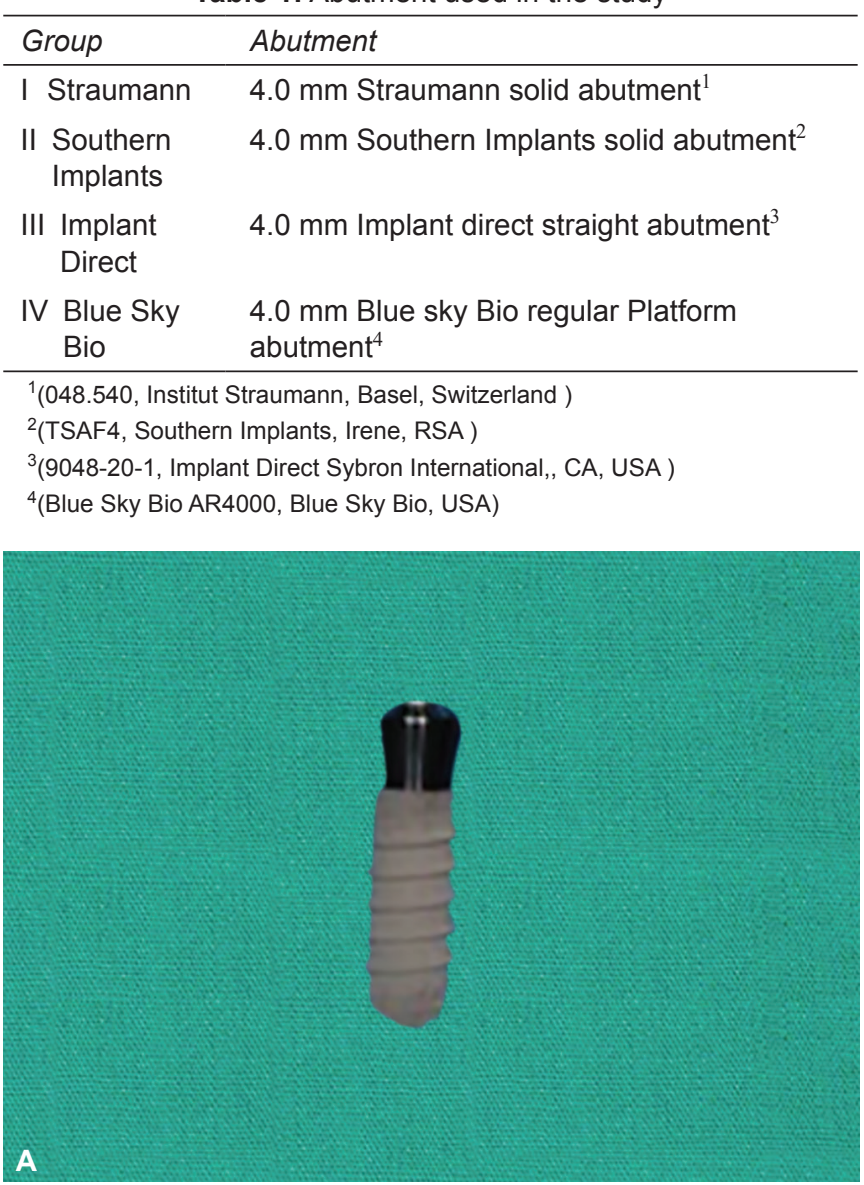

Figs 1A and B: (A) Straumann tissue-level implants; (B) Different types of abutments

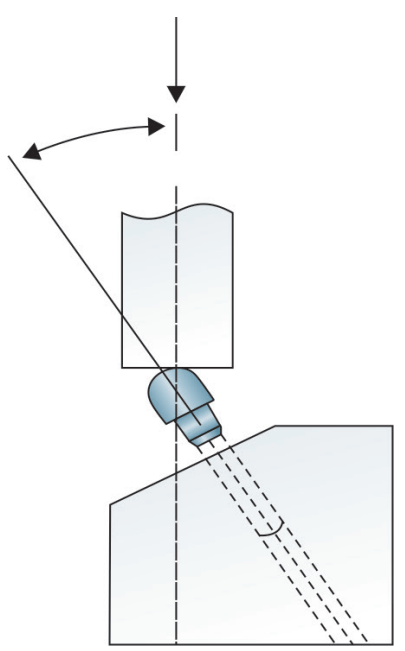

Fig. 2: Schematic diagram of the testing condition test for endosseous dental implants (Fig. 3). An electric torque controller (iSD900 NSK, Tochigi-ken, Japan) was used to tighten the abutments at $35 \mathrm{Ncm}$. After 10 minutes, the same tightening torque was applied to compensate for the loss of preload caused by surface settling of the interface. Another 10 minutes later, the removal torque before loading was measured using a digital torque gauge HTG2- 200Nc (IMADA, Toyohashi, Japan). The dynamic Loading Fatigue Tester (MTS 810 Material Test Systems Co., Minnesota, USA) (Fig. 4) was installed to produce human-like chewing movement by using a cam and motor. The ratio of removal torque and tightening torque before and after loading can be a sign of how much loosening occurs before and after loading respectively. To guarantee the load accuracy it was calculated before the experiment. As the cam rotates, the cam-housing cylinder makes contact with the implant and produces chewing-like forces to it. A cylindrical weight located on the top of the cam was used to keep the loads among 100 to 500 N. A digital force gauge was used to calculate each applied load. In all experiments, a $150 \mathrm{~N}$ cyclic load at a frequency of $6 \mathrm{~Hz}$ were applied for
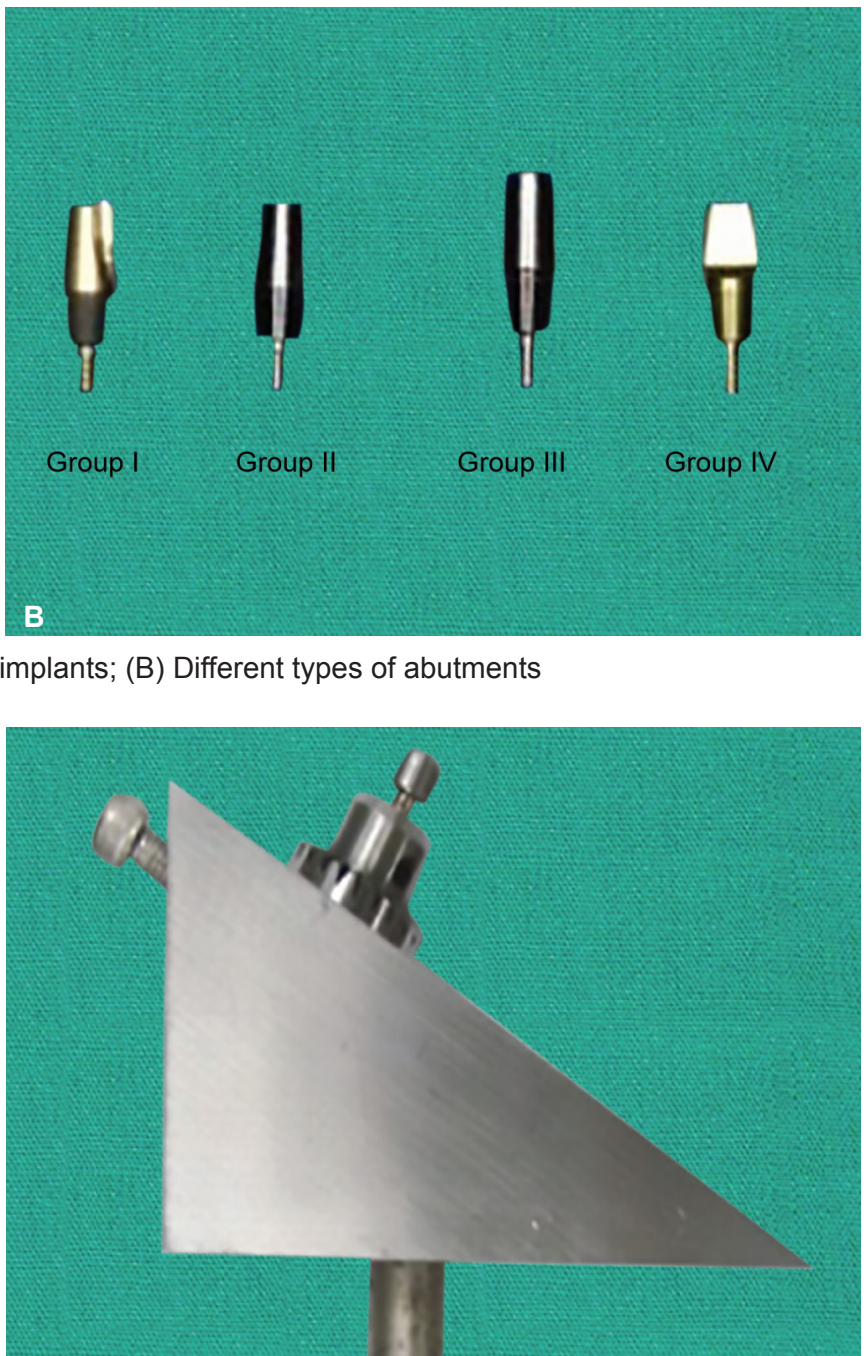

Fig. 3: Customized jig 


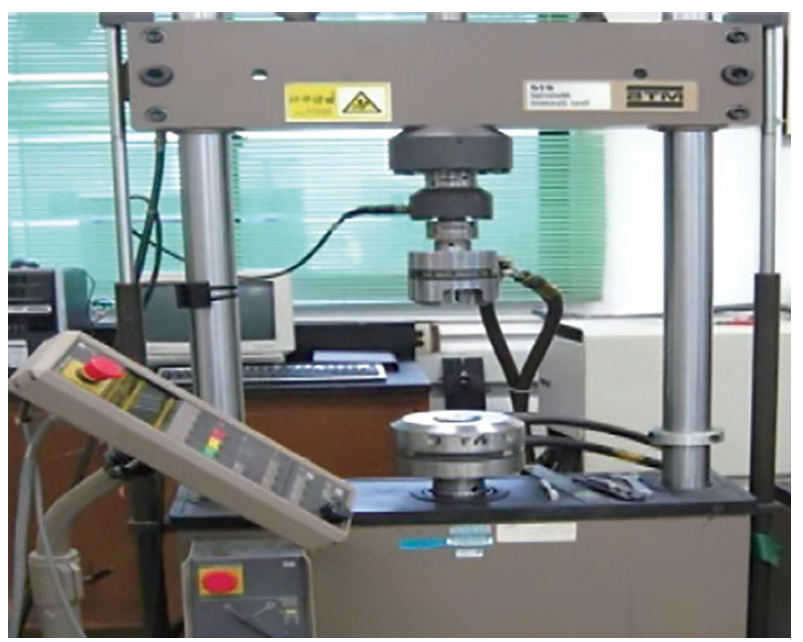

Fig 4: Dynamic loading fatigue tester

1 million cycles was applied to the implant at a 30-degree angle to the long axis to the implants. Before loads were applied, the Periotest value (PTV) was measured by Periotest device (Siemens AG, Bensheim, Germany). A point was marked, $2 \mathrm{~mm}$ from the most apical point of the abutment, to measure the PTV. After every 100,000 loads, the abutments were examined for any deformation. Another PTV was measured after 1 million loads had been applied. Then, a digital torque gauge (MGT 12, Mark-10) was used to measure the RTV for each specimen.

The data were analyzed statistically using SPSS statistical software for Windows (version 16.0, SPSS, IBM, New York, USA). Kruskal-Wallis tests and one-way analysis of variance (ANOVA) were used to compare RTVs and PTVs after application of equal loads for each group. The Spearman correlation coefficient was applied to compare RTVs and PTVs after loading.

\section{RESULTS}

The RTVs and PTVs for each group were shown in Tables 2 to 4 . There was an insignificant difference in PTVs between groups ( $p>0.05$ ) before cyclic loading (Table 2). After cyclic loading, there were no fractures of abutments or implants in groups I or II. However, fractured components
Table 2: Initial periotest values (PTVS) before cyclic loading in all groups.

\begin{tabular}{lllllllll}
\hline Group & \multicolumn{1}{c}{ Abutment number } & \multicolumn{1}{c}{ Mean \pm SD } \\
\hline & 1 & 2 & 3 & 4 & 5 & 6 & 7 & \\
I & -4 & -4 & -4 & -4 & -4 & -4 & -4 & $-4.00 \pm 0.00$ \\
II & -5 & -4 & -4 & -4 & -5 & -4 & -5 & $-4.43 \pm 0.53$ \\
III & -5 & -4 & -5 & -5 & -4 & -6 & -4 & $-4.71 \pm 0.57$ \\
IV & -5 & -5 & -4 & -4 & -4 & -6 & -4 & $-4.57 \pm 0.58$ \\
\hline
\end{tabular}

were observed in groups III and IV. It was unfeasible in group III to compare between groups because six abutments were fractured. After cyclic loading (Table 3), the mean PTV of group I was statistically significantly lower than those of groups II and IV (Kruskal-Wallis test, $p=0.003$; one-way ANOVA, $p<0.05$ ). Although the PTV of group II was lower than that of group IV, this difference was not statistically significant $(p>0.05)$. With respect to mean PTVs before $(-4.29 \pm 0.47)$ and after $(4.76 \pm 5.58)$ cyclic loading, the mean PTV after loading was statistically significantly higher for all groups ( $p<0.05)$. The RTV of group I was higher than those of groups II and IV (Table 4).

There were significant differences between The RTVs of the three groups (I, II, and IV) $(\mathrm{p}=0.002)$. In making individual comparisons per group via one-way ANOVA, the RTV of group I was statistically significantly greater than those of groups II and IV ( $p<0.05)$. While the RTV of group II was greater than that of group IV, the difference was not statistically significant ( $p>0.05$ ).

The Spearman test was used to compare RTVs and PTVs after cyclic loading. As the PTV increased after cyclic loading, RTV decreased in an inverse proportion $(\mathrm{p}=-0.992, \mathrm{p}<0.01)$.

The abutment fractures were apparent in six of the seven groups III samples, while the implant fractures were found to have occurred near the bottom of the abutment screw in the fractured group IV samples.

\section{DISCUSSION}

Numerous studies of a prosthodontic problem with implants consider screw loosening, as the most familiar cause of failure..$^{2,3,7,8}$ Failure, often appears in single-

Table 3: Final periotest values (PTVs) after cyclic loading in all groups

\begin{tabular}{lllll}
\hline Abutment number & Group I & Group II & Group III & Group IV \\
\hline 1 & -5 & +1 & +17 & +15 \\
2 & -4 & +5 & Fracture at $(\sim 750,000$ cycles $)$ & +8 \\
3 & -4 & +3 & Fracture at $(\sim 500,000$ cycles $)$ & +7 \\
4 & -4 & +3 & Fracture at $(\sim 750,000$ cycles $)$ & Fracture at $(\sim 700,000$ cycles $)$ \\
5 & -5 & +8 & Fracture at $(\sim 700,000$ cycles $)$ & Fracture at $(\sim 500,000$ cycles $)$ \\
6 & -4 & +12 & Screw fracture $(\sim 700,000$ cycles $)$ & Fracture at $(\sim 750,000$ cycles $)$ \\
7 & -5 & +14 & Fracture at $(\sim 500,000$ cycles $)$ & Fracture at $(\sim 750,000$ cycles $)$ \\
Mean \pm SD & $-4.42 \pm 0.53$ & $6.57 \pm 4.71$ & $17.00 \pm 0.00$ & $10 \pm 4.04$ \\
\hline
\end{tabular}


Table 4: Removal torque value (RTVs) mean and standard deviation in all groups

\begin{tabular}{lllll}
\hline Abutment no. & Group 1 & Group 2 & Group 3 & Group 4 \\
\hline 1 & 42.5 & 32.0 & 12.0 & 17.0 \\
2 & 36.0 & 22.0 & Fracture of Screw & 22.0 \\
3 & 32.0 & 24.5 & Fracture of Screw & 23.0 \\
4 & 34.0 & 26.0 & Fracture of Screw & Fracture of the fixture \\
5 & 37.0 & 22.0 & Fracture of Screw & Fracture of the fixture \\
6 & 35.0 & 18.0 & Fracture of Screw & Fracture of the fixture \\
7 & 36.0 & 17.0 & Fracture of Screw & Fracture of the fixture \\
Mean \pm SD & $36.07 \pm 2.74$ & $23.07 \pm 5.46$ & $12.00 \pm 0$ & $20.67 \pm 3.21$ \\
\hline
\end{tabular}

$\mathrm{SD}=$ standard deviation

tooth implant restorations in the molar area. Inadequate preload, fatigue, settling effect, vibrating micromovement, inadequate joint dimensions between implants and counterpart abutments, and excessive occlusal loads are considered the most common causes of screw loosening. It takes place in two stages. Compressive force between the implants and abutment systems and screw elongation occurs as a result of the application of tightening torque to the abutment screw. This leads to wear and/or sliding of the threads of the implant with the application of functional chewing forces to the implant prosthesis, and this will cause preload of the screw and finally loss of direct contact between the screw and the implant.

Several studies have revealed that external connections are more liable to screw loosening than internal connections $^{7-10}$ and providing the abutment with a friction fit and positive locking within the implant as in the Morse taper structure will make it more resistant to loosening. Clinical and experimental studies reveal that the Straumann solid abutment has superior mechanical advantages. ${ }^{11,12}$ At this time, it is not uncommon to apply different abutments produced by different companies, but there is a lack of information on the loosening of screws when such interchangeable abutments are used. So, this study evaluated screw loosening of different abutments connected to internal-hex implants after cyclic loading.

Three-dimensional (3D) deviations of the nine interchangeable abutment groups connected to the tapered Screw-Vent implants were studied by Gilbert et al. ${ }^{12}$ and they found that the compatible copy abutments of other companies showed more displacement than the original abutment.

Kim et al. ${ }^{13}$ evaluated the screw loosening with different abutments and they concluded that abutments from the different manufacturers can be used interchangeable with each other, but they have different physical and chemical properties which cause the screw loosening, abutment fracture, or the implant fracture.

No implant or abutment fracture occurred in group I (Straumann solid abutment). So it is considered the most stable and resistant to the loosening of a screw as the
RTVs and PTVs after cyclic loading in this group show a superior outcome than the other groups. Although the group II southern Implants did not show any implant or abutment fractures, its mean RTV was lower, and its mean PTV after the cyclic loads was higher than those of group I. This provides evidence that it displayed less resistance to screw loosening than group II. Group III exhibited six fractured abutment screws, and group IV showed four fractured implants. This may be as a result of differences in mechanical fit and accuracy of different implant systems.

The overall success of implant prosthesis depends mainly on the Stability of the connection between the implant and abutment. Several factors such as accurate fit between components, machining accuracy, saliva contamination, and screw preload are very important to connection stability. The mechanical fit and accuracy of the implant system components are important because it is highly probable that screw loosening is strongly influenced by the accuracy of fit of at the interface between the implant and abutment. ${ }^{14}$ When investigating studies on the loosening of a screw based on different physical characteristics, Martin et al. ${ }^{15}$ speculated that a screw with a pure gold coating allows for the weakening of surface material and the coefficient of friction changes to prevent the screw from loosening. The contact length, materials, and physical characteristics of screws must be considered as factors that may affect the loosening torque. ${ }^{16}$ The fracture strengths of the implants and abutments used in the experiment-the Straumann solid abutment, southern implants, the implant direct abutment, and the Blue Sky Bio-are 550 N, 350 N, 413 N, 300 N, and 650 N, respectively. Implant Fractures are seen in group IV abutments (Blue Sky Bio), this can be explained as they have higher fracture strength than that of the Straumann implants. While fracture of the screws are seen in group III as they exhibit lower fracture strength than that of the Straumann implants. Implants from the Blue Sky Bio have fracture strength of $1,727 \mathrm{~N}$, which is much higher than that of the Blue Sky Bio solid abutment; so, totally different results would be expected if Blue Sky Bio-implants were connected to the abutments used in the present study. 
In this experiment, removal torque testing was performed and PTVs were assessed to determine the stability of the screw joint between implants and abutments. In addition to this particular method, a strain gauge could also be used to measure the deformation of screw lengths and the fracture strength of abutments or RTVs. Although removal torque testing is clinically simple and easy to perform, the results of this test have some limitations because of different temperatures or erosion. ${ }^{17-19}$

The PTV, which generally reveals any tendency of screws to loosen and is readily available for clinical purposes, was employed in this experiment. In group I, the PTVs after cyclic loading ranging from -4 to +2 , implying that every single structure in the group would be clinically stable.

One abutment (ITI solid abutment) yielded an RTV of $40.5 \mathrm{Ncm}$, which was greater than the initial insertion torque; however, the remaining RTVs and the mean RTV decreased by $5 \%$ from the initial torque. Thus, cold welding would not be expected to occur for this group. The initial removal torque was $10 \%$ to $15 \%$ greater than the insertion torque, and the removal torque after cyclic loading was not reduced any less than the tightening torque. ${ }^{20}$ However, Squier et al. ${ }^{21}$ insisted that RTVs for standard and synOcta Straumann implants were lower than insertion torque values. The actual insertion torque applied to an implant may vary, even when a torque controller is used. ${ }^{22}$ Moreover, changes in the tightening torque when a torque controller is used will not affect removal torque in any way; the correlation of these torques has been investigated carefully. The torque controller used in this experiment was a Straumann hand ratchet-type torque wrench that is capable of applying consistent tightening torques with a range of error that is less than $10 \%{ }^{23}$

The load in this experiment was set at $150 \mathrm{~N}$, which is about the midpoint between the maximum chewing forces in the anterior arch $(109 \mathrm{~N})$ and the posterior arch (250 N). One million loads were applied to the implantabutment assemblies in this experiment. To reproduce the clinical condition of implants, 240,000 or 300,000 cyclic loads are necessary, and 1 million cycles can be considered roughly equivalent to implants in clinical use for 3.5 to 4 years. $^{24}$

In the present study, the load was applied directly to the abutment, but clinically, the occlusal load is received by the crown, and the forces are distributed through the implant and abutment. Therefore, in clinical conditions, the results might be quite different. In this study, groups III and IV experienced a considerable number of fractures, and this may have biased the results. Further clinical and laboratory studies are necessary to attain more reliable results.

\section{CONCLUSION}

The RTVs of the different copy abutments was lower than those of the original Straumann abutment. The reduction rate of the Straumann solid and Blue Sky Bio regular platform abutments was lower than those of other copy abutments. Abutments from the different manufacturers have different physical and chemical characteristics so there will be a potential risk of mechanical failure when the interchangeable abutments are used. So, the use of an abutment manufactured by the same implant company is highly recommended for the avoidance of loosening of the abutment screws. This study does not represent sufficient data to support an authoritative conclusion.

\section{CLINICAL SIGNIFICANCE}

The use of an abutment manufactured by the same implant company is highly recommended for the avoidance of loosening of the abutment screws.

\section{REFERENCES}

1. Theoharidou A, Petridis HP, Tzannas K, Garefis P. Abutment screw loosening in single-implant restorations: a systematic review. Int J Oral Maxillofac Implants. 2008;23(4):681-690.

2. Michalakis KX, Calvani P, Muftu S, Pissiotis A, Hirayama H. The effect of different implant-abutment connections on screw joint stability. J Oral Implantol. 2014 Apr;40(2):146-152.

3 Venturea J, Jimenez-Castrllanos E, Romero J, Enrile F. Tooth fracture in fixed full arch implant supported acrylic resin prostheses: A retrospective clinical study. Int J Prosthodont 2016;29:161-165.

4. Bansal S, Aras MA, Chitre V. Guidelines for treatment planning of mandibular implant overdenture. J Dent Implant 2014;4(1):86-90.

5. Tunchel S, Blay A, Kolerman R, Mijiritsky E, Shibli JA. 3D printing/additive manufacturing single titanium dental implants: A prospective multicenter study with 3 years of follow-up. Int J Dent 2016;5:1-9.

6. Schwarz MS. Mechanical complication of dental implants. Clin Oral Implants Res 2000;11:156-158.

7. Sutter F, Weber HP, Sorensen J, Belser U. The new restorative concept of the ITI dental implant system: Design and engineering. Int J Periodontics Restorative Dent 1993;13(5):408-431.

8. Carneiro TD, Dietrich L, Prudente MS, da Silva Neto JP, do Prado CJ, De Araújo CA, et al. Fracture Resistance of Internal Conical and External Hexagon: Regular and Narrow ImplantAbutment Assemblies. Implant Dent. 2016 Aug 1;25(4):510-514.

9. Merz BR, Hunenbart S, Belser UC. Mechanics of the implantabutment connection: An 8-degree taper compared to a buttjoint connection. Int J Oral Maxillofac Implants 2000;15(4):519-526.

10. Khraisat A, Stegaroiu R, Nomura S, Miyakawa O. Fatigue resistance of two implant/abutment joint designs. J Prosthet Dent 2002;88: 604-610.

11. Cehreli MC, Akca K, Iplikcioglu H, Sahin S. Dynamic fatigue resistance of implant-abutment junction in an internally notched Morse taper implant: Influence of abutment design. Clin Oral Implants Res 2004;15(4):459-465. 
12. Gilbert AB, Yilmaz B, Seidt JD, McGlumphy EA, Clelland NL, Chien $\mathrm{HH}$. Three-dimensional displacement of nine different abutments for an implant with an internal hexagon platform. Int J Oral Maxillofac Implants 2015;30(4):781-788.

13. Kim SK, Koak JY, Heo SJ, Taylor TD, Sook R, Lee SY. Screw loosening with interchangeable abutments in internally connected implants after cyclic loading. Int J Oral Maxillofac Implants 2012;27(1):42-47.

14. Veeraiyan DK. Textbook of Prosthodontics. The Health Sciences. Japee Brothers Medical Publisher (P) Ltd Publisher. 2017; 2nd. Ed. p. 1055-1079.

15. Martin WC, Woody RD, Miller BH, Miller AW. Implant abutment screw rotations and preloads for four different screw materials and surfaces. J Prosthet Dent 2001;86(1):24-32.

16. Sakaguchi R, Ferracane J, Powers J. Craig's Restorative Dental Materials Elsevier, Inc 2018; 14th. ed. p. 66-69.

17. Cibirka RM, Nelson SK, Lang BR, Rueggeberg FA. Examination of the implant-abutment interface after fatigue test. J Prosthet Dent 2001;85(3):268-275.

18. Hoyer SA, Stanford CM, Buranadham S, Fridrich T, Wagner J, Grat- ton D. Dynamic fatigue properties of dental implant- abutment interface: Joint opening in wide-diameter vs standarddiameter hex-type implants. J Prosthet Dent 2001;85(6):599-607.

19. Faulkner MG, Wolfaard JE, Chan A. Measuring abutment/ implant joint integrity with the Periotest instrument. Int J Oral Maxillofac Implants 1999;14(5):681-688.

20. Norton MR. Assessment of cold welding properties of the internal conical interface of two commercially available implant systems. J Prosthet Dent 1999;81(2):159-166.

21. Squier RS, Psoter WJ, Taylor TD. Removal torques of conical, tapered implant abutment: The effect of anodization and reduction of surface area. Int J Oral Maxillofac Implants 2002;17(1):24-27.

22. Kim JM, Han JS, Lee JB. A study of screw loosening after dynamic continuous fatigue test of several abutment screw. J Korean Acad Prosthodont 2003;41(4):519-530.

23. Standlee JP, Caputo AA, Chwu MY, Sun TT. Accuracy of mechanical torque-limiting devices for implants. Int J Oral Maxillofac Implants. 2002 Mar 1;17(2):220-224.

24. Stegaroiu R, Yamada H, Kasukari H, Miyakawa O. Retention and failure mode after cyclic loading in two post and core systems. J Prosthet Dent 1996;75(5):506-511. 